\title{
DEFICIÊNCIA: A LUTA DE SÉCULOS PELA INCLUSÃO SOCIAL E CIDADANIA
}

\author{
DEFICIENCY: THE FIGHT OF THE CENTURIES PER SOCIAL INCLUSION AND \\ CITIZENSHIP
}

Helena Beatriz de Moura Belle

Graduada em Direito e em Ciências Contábeis pela Pontifícia Universidade Católica de Goiás, especialista em Direito e Advocacia Empresarial, em Direito Educacional, em Análise e Auditoria Contábil, mestre em Gestão de Negócios, doutora em Educação com ênfase em políticas e gestão organizacional, com pós-doutorado em Ciências Jurídicas; professora na PUC Goiás; coordenadora do Curso de Direito da Faculdade Evangélica de Goianésia.

E-mail: helenabeatrizmb@hotmail.com

Helen Samara da Silva Costa

Graduanda em Direito pela Pontifícia Universidade Católica de Goiás, atua no programa de Monitoria pela PUC Goiás, é pesquisadora no Programa de Iniciação Científica da PUC Goiás.

E-mail: helensamarac@gmail.com

Recebido em: 01/07/2018

Aprovado em: 16/02/2019

RESUMO: No presente estudo tem-se por escopo discutir a evolução histórica da acepção da deficiência, bem como as alterações de seus significados, como fulcro na descrição do processo evolutivo desta abordagem, carente de atenção em sua efetividade. $\mathrm{O}$ trabalho foi norteado pelo método dedutivo, que consiste na análise de uma premissa geral, para se alcançar uma premissa particular, com base na metodologia de pesquisa qualitativa e adoção de técnicas de estudos em doutrinas especializadas, assim como artigos científicos que tratam do tema e fontes primárias, quais sejam os fundamentos constitucionais e infraconstitucionais. Constatou-se que pessoas com deficiência sofreram inúmeras formas de abusos e discriminação, foram exterminadas ou abandonadas durante milênios e a discriminação ainda perdura. Decorridos séculos de lutas, as pessoas deficientes vêm, lentamente, conquistando espaço na sociedade; busca-se igualdade, respeito, reconhecimento de habilidades e competências, inclusão social e cidadania, todavia, para a efetividade desses direitos é imprescindível a atuação rigorosa do Estado e da família, bem como, promoção e incentivo de forma colaborativa por toda a sociedade, conforme os ditames constitucionais.

Palavras-Chave: Direitos Humanos. Deficiência. Evolução Conceitual. Cidadania.

ABSTRACT: In the present study, the purpose of this study is to discuss the historical evolution of the meaning of disability, as well as the changes of its meanings, as a fulcrum in the description of the evolutionary process of this approach, lacking attention in its effectiveness. The work was guided by the deductive method, which consists of the analysis of a general premise, to reach a particular premise, based on the methodology of qualitative research and adoption of techniques of studies in specialized doctrines, as well as scientific articles that deal with the subject and primary sources, which are the constitutional and infraconstitutional foundations. It has been found that persons with disabilities have suffered numerous forms of abuse and discrimination, been exterminated or abandoned for millennia, and discrimination still persists. After centuries of struggle, disabled people have slowly gained space in society; we seek equality, respect, 
recognition of skills and competences, social inclusion and citizenship. However, for the effectiveness of these rights, it is essential that the State and the family act in a rigorous manner, as well as promotion and encouragement in a collaborative way throughout society, according to the constitutional dictates.

Keywords: Human Rights. Deficiency. Conceptual Evolution. Citizenship.

SUMÁRIO: Introdução; 1 Histórico da pessoa com deficiência no mundo; 2 Evolução dos significados e percepção de modelos de deficiências declarados; 2.1 Evolução das terminologias adotadas para identificação de pessoas com deficiência; 2.2 Modelo médico e modelo social; 2.3 A influência das classificações internacionais na definição de deficiência; Conclusão; Referências.

\section{INTRODUÇÃO}

No percurso da história mundial a compreensão do que vem a ser deficiência sofreu diversas alterações. A pessoa com deficiência foi segregada da sociedade e isto ainda está presente. Desrespeito, discriminação e falta de atenção estão presentes na escola, nos órgãos públicos, nas organizações de natureza privada, no acesso as vias, ao transporte, e tantos outros, provocando sofrimento e insatisfação a pessoa com deficiência e, também, de seus familiares.

A acepção da deficiência sofreu diversas alterações ao longo da história mundial, assim como a definição e a classificação da deficiência no plano internacional, que influenciou e influencia a conceituação da deficiência na legislação brasileira.

A Convenção Internacional sobre os Direitos das Pessoas com Deficiência e seu Protocolo Facultativo, assinados em Nova York, em 30 de março de 2007, foi ratificada no ordenamento jurídico brasileiro com força de emenda constitucional, conforme disposto na Constituição Federal de 1988 , artigo $5^{\circ}, \S 3^{\circ}$, tomado força no ordenamento legal brasileiro, por meio do decreto $\mathrm{n}^{\circ} 6.949$, de 25 de agosto de 2009 (Dec. $n^{\circ}$ 6.949/2009). Trata-se da primeira Convenção de direitos humanos validada no ordenamento jurídico brasileiro.

Não obstante, este decreto permaneceu sem aplicabilidade pela falta de norma infraconstitucional que regulasse a situação da pessoa com deficiência no ordenamento jurídico. Por esse motivo o Congresso Nacional promulgou a Lei ${ }^{\circ} 13.146$, de 06 de julho de 2015 (Lei $n^{\circ}$ 13.146/2015), denominada Estatuto da Pessoa com Deficiência, introduziu e alterou, por consequência, vários dispositivos no Código Civil vigente, com o intuito de assegurar e promover, em condições de igualdade, o exercício dos direitos e das liberdades fundamentais por pessoa com deficiência, visando à sua inclusão social e cidadania, isto é, igualar a pessoa com deficiência com as demais pessoas, para efetivar a inclusão social dos deficientes.

A maneira como a deficiência foi compreendida no decorrer da história da humanidade, que ainda é carente de debates e publicações, assim como, a transformação conceitual e terminológica da deficiência, serão temáticas abordadas no presente estudo, para que se possibilite a compreensão dos motivos que levaram a criação da convenção dos direitos das pessoas com deficiência, e, por conseguinte, a promulgação do Estatuto da Pessoa com Deficiência no Brasil.

No decorrer desta pesquisa será discutida a evolução histórica da acepção da deficiência no mundo, internacional e nacionalmente, bem como a transformação da definição da deficiência, respectivamente, como fulcro na descrição da evolução dos termos e da compreensão da deficiência em diversos momentos e localidades.

O estudo será amparado pelo método dedutivo, que segundo Marconi e Lakatos (2010, p. 74), consiste na análise de uma premissa geral, para se obter uma premissa particular, com o propósito de explicar o conteúdo das premissas. Ainda conforme as autoras (2010, p. 157) a pesquisa será realizada com base na metodologia de pesquisa qualitativa, a partir de documentação indireta escrita, com o uso de técnicas de estudos em doutrinas especializadas e artigos científicos (pesquisa bibliográficas), e também em fontes primárias (pesquisa documental), quais sejam, os 
fundamentos constitucionais e infraconstitucionais, acordos e convenções inerentes ao tema, que propiciaram a análise e interpretação do tema proposto.

\section{HISTÓRICO DA PESSOA COM DEFICÊNCIA NO MUNDO}

No decorrer da história da humanidade verificou-se que a pessoa com deficiência era deixada de lado, em muitos casos, separada do convívio social e era comum o abandono e morte dessas pessoas, sendo tolhidas dos direitos básicos que todo ser humano faz jus, como a dignidade, igualdade, educação, saúde, habitação e alimentação.

As atitudes truculentas eram justificadas, por vezes, pelo místico e divino. Acreditava-se que os deficientes eram possuidores de maus espíritos e por essa razão não poderiam conviver em sociedade como os demais membros da sociedade e, consequentemente, as pessoas acometidas por quaisquer deficiências, eram recolhidas ou exterminadas.

Estas práticas de crueldade, infelizmente, eram comuns em todos os países na antiguidade; as justificativas eram as mais estapafúrdias possíveis; os sacrifícios eram cometidos com justificativas de que o descontentamento dos deuses estava diretamente relacionado às deficiências das pessoas, notadamente quando esta condição fosse identificada no próprio nascimento. Nesta acepção, Braddock e Parish (2001) apud., Hosni (2016, p. 38), explicam que:

Na Grécia Antiga no Império Romano, a ira dos deuses era tida como causa da deficiência quando essa era congênita, o que tornava aceitável a prática de sacrifício ou abandono do recém-nascido; já o deficiente que adquiriu sua condição no trabalho ou na guerra não recebia rótulo totalmente negativo, sendo satisfatoriamente integrado à sociedade, e algumas vezes, sendo destinatário de políticas de auxílio quando não era apto a trabalhar.

Como se verifica, a ignorância sobre o assunto estava sempre presente, a ponto de se considerar o estado físico pelo nascimento e a deficiência adquirida em outras fases da vida, especialmente no exercício da atividade laboral. Mecloy, apud., Costa e Fuzzeto (2017, p. 403), complementa, mediante abordagem específica, desta vez envolvendo deficiência visual, explica que: A eliminação dos cegos e dos considerados inválidos não se dava somente pelas difíceis
condições de vida da época. Nas sociedades primitivas, acreditava-se que as pessoas cegas
eram possuídas por espíritos malignos e manter uma relação com essas pessoas significava
manter uma relação com um espírito mau. O cego, então, convertia-se em objeto de temor
religioso. Em outros casos, muito frequentes entre os primitivos, a cegueira era
considerada um castigo infligido pelos deuses, e a pessoa cega levava em si mesma o
estigma do pecado cometido por ele, por seus pais, seus avós ou por algum membro da
tribo.

Nota-se que, nesta argumentação, há explícita fragilidade na compreensão sobre deficiência e, de maneira especial, a necessidade que tem o indivíduo, que se considera eficiente, para banir aquele que foge às regras impostas pela sociedade, isto é, se alguém não possuir estado físico e/ou mental com os padrões aceitos, deve ser tratado como diferente, desigual, mau, assim, fadado ao esquecimento ou morte.

Não diferente era a compreensão dos povos na Grécia e na Roma Antigas, entretanto, o extermínio de pessoas deficientes era comum pela razão de não possuírem aptidão física para lutar nas guerras. Desse modo, os deficientes se não podiam contribuir nos conflitos bélicos eram descartados ao nascer, sendo mortos ou abandonados.

O tratamento dispensado aos deficientes físicos à época de conflitos bélicos entre povos antigos era justificado, pelos agressores, em geral, na perspectiva da necessidade da perfeição, força e resistência necessárias nos combates, então, eficiência e eficácia do indivíduo, eram condições indispensáveis e, também os pais e familiares deveriam concordar e conduzir a pessoa 
com imperfeição para que fossem abandonada ou exterminada a depender do grau de deficiência. Em sentido convergente argumentam Costa e Fuzzeto, que:

Por privilegiar a excelência nos conflitos bélicos, a comunidade espartana pregava a perfeição física como ideal máximo atingível aos homens. Com isso, os genitores tinham obrigação de apresentar o filho recém-nascido a um conselho formado por anciãos de notória autoridade para que fosse feita uma avaliação. Aqueles que apresentassem defeito ou fragilidade eram lançados do alto do monte Taigeto. A famosa pólis grega Atenas, entendida como o berço da civilização ocidental, não divergia da cidade-estado grega citada acima. Assim, tinha-se como prática, além da eliminação, abandonar os bebês que nasciam com deficiência em uma vasilha de argila. Tais condutas também eram comuns na civilização romana (COSTA; FUZZETO, 2017, p. 403).

O estado ideal, físico e mental, impactava na sobrevivência da pessoa. Nota-se que as práticas de eliminação e abandono eram tão corriqueiras e comuns, que grandes filósofos da antiguidade, como Platão e Aristóteles, apoiavam o extermínio das pessoas com deficiência, conforme estudos de Costa e Fuzzeto:

Platão afirmou: 'no que concerne aos que receberam corpo mal organizado, deixa-os morrer (...) quanto às crianças doentes e às que sofrerem qualquer deformidade, serão levadas, como convém, a paradeiro desconhecido e secreto'. Quanto a Aristóteles, seu pensamento pode ser assim resumido: 'quanto, a saber, quais as crianças que se deve abandonar ou educar, devesse haver uma lei que proíba alimentar toda criança disforme (SILVA apud., COSTA; FUZZETO, 2017, p. 403).

Estas compreensões e condutas eram convergentes com as adotadas na Grécia e Roma, tanto quanto ao extermínio quanto no esquecimento da pessoa com deficiência, ou seu afastamento do convívio social, inclusive, a procura de meios para amenizar o mau, ironicamente, ao não revelar o paradeiro destas pessoas, como se fosse obra do acaso.

A propagação do Cristianismo impactou em algumas mudanças quanto a concepção da deficiência, baseado nos ensinamentos de Cristo. Este entendimento é apontado por Costa e Fuzzeto (2017, p. 404), com argumentos de que o ser humano passou a ser visto como imagem e semelhança de Deus, e por esse motivo era merecedor do amor e misericórdia divina. A partir dessas premissas a Igreja Católica criou instituições para oferecer cuidados a pessoa com deficiência.

Na Idade Média, apesar da mudança nas conceituações e paradoxos sobre a condição física e mental, o deficiente ainda era percebido e tratado como fruto do pecado, destarte, a única forma de admitir ou aceitar esta condição seria através da caridade ou da penitência religiosa. Percebe-se que as acepções, até então, eram provenientes do plano espiritual, baseado em entidades divinas, todavia, ao envolver a religiosidade, aduz Fonseca (2012), difundiu-se o ideário de isolamento do deficiente em instituições beneficentes, evitando o extermínio, entretanto, perdurando o preconceito e a injustiça.

A concepção de deficiência com fundamentos nos preceitos religiosos, desta vez envolvendo o catolicismo, impactava em práticas e consequências ainda mais cruéis, justificada por questões divinas, ao invés de compreendida como medíocres. Zavarese apud., Costa e Fuzzeto (2017, p. 404), argumentam que:

Durante o período feudal, na era cristã o corpo diferente continua sendo relegado. $\mathrm{O}$ moralismo católico traduzia os deficientes como figuras representativas do pecado e as colocava diante da fogueira da inquisição. A dicotomia entre corpo diferente/alma reforçava a ideia da alma percebida como templo de Deus e corpo visto como oficina do diabo. 
Diante disso, nota-se que na Idade Média as deficiências, excepcionalmente as mentais, eram tratadas como advindas do sobrenatural, ao passo que o Renascimento e depois o Iluminismo propiciaram uma análise naturalista desse fenômeno de forma mais gradual, explicam, também, conforme expõe Braddock e Parish apud. Hosni (2016, p. 38).

A partir da Idade Moderna, conforme retratam Costa e Fuzzeto (2017, p. 404), a deficiência passou a ser vista como doença, e, portanto, era merecedora de cuidados e tratamento especial e, "isto só foi possível graças ao avanço da filosofia na época e ao nascimento de vertentes em que impulsionavam o conhecimento empírico. Através de estudos de anatomia, a deficiência começou a ser vista como uma doença, merecendo cuidado e tratamento especial".

Esta nova compreensão sobre a deficiência da pessoa, somada as discussões e pretensões advindas da Revolução Francesa, viabilizou o início do processo de inclusão social, oriundos de ideais de igualdade, liberdade e fraternidade, com viés de busca e alcance da justiça social para a humanidade. Assim, com o século XVIII (Iluminismo), surgiram novos institutos e instrumentos que ajudaram a pessoa com deficiência a ter uma vida mais digna.

A mudança de compreensão, do espiritual, divino e sobrenatural, para questões científicas, à época ainda empírica, mas, sobretudo, passíveis de análises experimentais, foi um avanço inconteste. Neste sentido, Braddock e Parish, apud., Hosni (2016, p. 39) explicam que:

[...] é nesse período, especialmente no século XVIII, que se verifica o início da educação de pessoas surdas, a diferenciação entre deficiências intelectuais e doenças mentais, bem como a difusão de asilos e hospitais para deficientes, especialmente os mentais, por toda Europa e colônias inglesas na América.

Deste modo, novas concepções fundadas no conhecimento, no saber, no estudo científico, apontaram para novos horizontes, neste tão sofrido caminhar, impactando, também, na disponibilização de recursos e serviços com vistas a melhoria da qualidade de vida de pessoas com deficiências. Notadamente, para aquelas que adquiriam alguma limitação no desenvolvimento de algum trabalho.

$\mathrm{Na}$ Revolução Industrial, em virtude das grandes produções e em grande escala, especialmente com a inserção das máquinas, combinadas com a inexistência de leis trabalhistas que resguardassem o trabalhador, era corriqueiro a ocorrência de acidentes, os quais resultavam, na maioria das vezes, em mutilações. O trabalhador acidentado que adquirisse uma deficiência, consequentemente, deixava de ser produtivo, acarretando no seu esquecimento e separação das demais pessoas, sendo obrigado a viver na miserabilidade (COSTA; FUZZETO, 2017, p. 404).

Os constantes acidentes e suas consequências nortearam a reflexão sobre a necessidade de atenção e melhoria quanto aos instrumentos destinados as pessoas com alguma deficiência, e seu manuseio, [...] "desenvolveram-se, assim, as muletas, as macas móveis, as cadeiras de rodas, a escrita Braille e a codificação das línguas de sinais, que evoluíram de mímica para sistemas linguísticos complexos" (FONSECA, 2012, p. 21)

Com isso, a institucionalização cresce no século XIX, com o intuito de buscar maior inclusão de deficientes, todavia, permanece e impulsiona a exclusão da pessoa com deficiência e, consequentemente, a segregação dessas pessoas determinadas entidades. Verificou-se que:

Apesar de importantes instituições terem surgido nesse período, como a Gallaudet University para surdos, a institucionalização, em apreensão ampla, contribui para a objetificação da deficiência, sua identificação cada vez mais forte com causas biológicas de viés médico e gradual segregação dos deficientes nessas instituições (BRADDOCK e PARISH apud. HOSNI, 2016, p. 39).

Esta coisificação, embora importante no processo evolutivo sobre os direitos da pessoa com deficiência, ainda gerava constrangimento e decepção àqueles que sofram e ainda sofrem com limitações de diversas modalidades. 
Os vários estudos e novas percepções sobre o tratamento dispensado as pessoas com deficiência, ainda incipiente, deixou a desejar quanto aos benefícios, em decorrência da perversidade de muitos povos e especialistas. Veja-se que na teoria da eugenia ("bem-nascido"), idealizada por Francis Galton, no final do século XIX até a primeira metade do século XX, pregava reprodução de seres humanos melhores e perfeitos. Continua a perseguição aos deficientes e, por conseguinte, a esterilização forçada de inúmeras pessoas com deficiência. As condições físicas e psíquicas do ser humano foram associadas aos problemas sociais. "A situação piora, enfim, com o desenvolvimento da teoria da eugenia. A deficiência passa a ser vista como ameaça social e seus portadores têm sua imagem ligada a estudos sobre comportamentos desviantes e criminalidade" (BRADDOCK e PARISH, apud., HOSNI, 2016, p. 39).

O movimento eugênico propagou o modelo médico de deficiência, que posteriormente tornou-se o modelo padrão, impulsionando, ainda mais, a exclusão, segregação e tratamentos degradantes as pessoas deficientes.

Não bastasse o movimento "eugênio", para impedir avanços e melhorias na qualidade de vida de pessoas com deficiência, na segunda Guerra mundial (1939-1945) intensificou-se o extermínio, não somente destas como de todas as demais pessoas consideradas inferiores racialmente e economicamente, como ocorreu com judeus, negros e homoafetivos, culminando com práticas desumanas e bárbaras.

Doravante, a comunidade mundial se uniu para combater tais atrocidades deste tempo infame, e também para evitar que esses tipos de atitudes perdurassem novamente. Neste cenário, argumentam Costa e Fuzzeto (2017, p. 405), surge a Declaração Universal dos Direitos Humanos com intuito de garantir direitos básicos a toda e qualquer pessoa, sem formas de distinção.

Neste entendimento Fonseca (2012), explicando sobre a participação da população nas escolhas de seus governantes e, também, das leis promulgadas, deliberações e decisões, ainda que o regime identificado seja o democrático, que explica que a:

Declaração Universal dos Direitos Humanos decorreu da triste constatação histórica de que a maioria, por si só, não assegura a democracia, podendo, ao contrário, agir de forma a solapar as bases da dignidade humana. Veja-se o que ocorrera na Alemanha nazista e na Itália fascista, que elegeram os representantes desses regimes, os quais, por sua vez, trataram de obter leis majoritariamente aprovadas para oprimir oficial e legalmente grupos escolhidos como párias a serem eliminados do convívio social. Incluam-se aí os judeus, os homoafetivos, os ciganos, as pessoas com deficiência, os adversários ideológicos, entre outros (FONSECA, 2012, p. 28).

A vista disso observa-se que a Declaração dos Direitos Humanos surge com o objetivo de evitar e denunciar atitudes que visam aniquilar direitos e garantias fundamentais, independentemente dos grupos atingidos e embora tais declaração têm por fim garantir o mínimo de direitos a todos, ainda carrega ideologias discriminatórias.

Desse modo, percebe-se que existiam duas fases de proteção dos direitos humanos. A primeira fase é compreendida como a de amparo dos direitos humano, trata-se de proteção genérica e abstrata, com base na igualdade formal e também na não discriminação. Já a segunda fase começa com a especificação do ser humano como sujeito de direitos, marcada pela proteção específica e especial declarada em tratados que visam eliminar a discriminação das minorias (PIOVESAN, 2012, p. 43).

Na década de 1950 iniciam-se movimentos sociais que buscavam tratamento igualitário e não discriminatório dos deficientes (BRADDOCK e PARISH, apud. HOSNI, 2016 p. 39). Nos anos 1960 e 1970 os deficientes começaram a receber assistência e tratamento humanitário com as práticas das primeiras políticas de caráter assistencialista e paternalista. Especificamente nos anos 1970 a formação da identidade dos grupos de deficientes e participação política pelos próprios 
deficientes, com propósitos claros quanto a autonomia e alcance de seus direitos, a vida e a participação efetiva na sociedade (HOSNI, 2016, p. 40).

Ressalva-se, segundo leciona Leonart, apud. Costa e Fuzzeto, (2017, p. 405), que as guerras e acidentes possuem a capacidade de transformar pessoas "normais", em deficientes. Com isso a sociedade começou a compreender que a pessoa com deficiência ou sem deficiência, continua sendo pessoa, e, assim, pode-se adquirir deficiências no decorrer da vida, e com tanta discriminação, tem-se que o esclarecimento, poderá reduzir, sobremaneira, as desigualdades sociais de pessoas deficientes e, também, eficientes, assim, denominadas.

No Brasil a educação especial direcionada as pessoas como deficiência teve início, oficialmente, em meados de 1850 e, em 1854, foi criado o Imperial Instituto dos Meninos Cegos. Em 1857 criou-se o Imperial instituto dos Surdos-Mudos. Depois do surgimento desses institutos, seguiram-se as tentativas da sociedade civil (religiosos, pais e profissionais da área) de criar instituições especializadas para fornecer atendimento educacional e clínico aos deficientes. Em 1973 foi criado o Ministério da Educação Especial (CENESP), explica Caiado (2009, p. 330).

No Brasil, orienta Caiado (2009, p. 331), "a partir da luta contra a ditadura militar os movimentos urbanos ressurgiram e se intensificaram pela construção da cidadania. Trabalhadores e grupos até então silenciados se reuniram e se organizaram em sindicatos, associações e conselhos".

Na década de 1980, quando a Organização das Nações Unidas (ONU), fixou o Ano Internacional das Pessoas Deficientes (AIPD), e, posteriormente, as Pessoas Portadoras de Deficiência (1983-1992), houve uma grande mobilização e visibilidade, motivando as discussões sobre as condições de vida da pessoa com deficiência. Essas mobilizações cresceram em vários países, e, no Brasil, aconteceu o $1^{\circ}$ Encontro Nacional de Entidades de Pessoas Deficientes (1980) em Brasília, com a participação de, aproximadamente, 1.000 pessoas, vindas de toda parte do país, incluindo cegos, surdos, deficientes físicos e hansenianos. Criou-se, oportunamente, a Coalizão Nacional de Pessoas Deficientes, que abarcava todas as áreas de deficiência. Nesse encontro, lembra Caiado (2009, p. 331), foi postulada a autonomia dos deficientes.

O Congresso Nacional promulgou a Lei 7.853 de 24 de outubro de 1989 (Lei no 7.853/1989), que dispunha sobre o apoio às pessoas com deficiência, sua integração social, sobre a Coordenadoria Nacional para a Integração da Pessoa com Deficiência (Corde), institui a tutela jurisdicional de interesses coletivos ou difusos dessas pessoas, disciplina a atuação do Ministério Público e define crime, dentre outras providências.

Atos normativos foram sendo promulgados, ainda que sem efetividade plena, no Brasil e em outros países, influenciados pela ação ostensiva de alguns líderes, dentre os quais destaca-se o Secretário Geral da ONU, Senhor Ban Ki-moon, que manifestou sobre o dia Internacional da Pessoa com Deficiência, em 03 de dezembro de 2011, proferindo a seguinte mensagem:

Juntos por um mundo melhor para todos incluindo pessoas com deficiências no desenvolvimento: Faz 30 anos desde que as Nações Unidas celebraram pela primeira vez o Dia Internacional dos Deficientes com o tema "Plena Participação e Igualdade". Durante este período, foram feitos progressos importantes para aumentar a conscientização sobre os direitos das pessoas com deficiências e fortalecer o quadro normativo para realizar estes direitos - do Programa de Ação Mundial (1982) à Convenção sobre os Direitos das Pessoas com Deficiência (2006). Mais e mais países estão se comprometendo a proteger e promover os direitos das pessoas com deficiência. No entanto, restam muitos desafios. Pessoas com deficiência vivenciam taxas altas de pobreza e privação e têm duas vezes mais chances de não receber tratamentos de saúde. Taxas de emprego de pessoas com deficiência em alguns países são tão baixas que correspondem a um terço das taxas da população em geral. Nos países em desenvolvimento, a lacuna nas taxas de frequência na escola primária entre crianças com deficiências e as outras variam de $10 \%$ a $60 \%$. Esta exclusão multidimensional representa um enorme custo, não só para as pessoas com deficiências, mas para a sociedade como um todo. Neste Dia Internacional dos Deficientes lembrem que o desenvolvimento só pode ser sustentável quando é igualitário, inclusivo e 
acessível a todos. Pessoas com deficiências precisam, portanto, ser incluídas em todas as etapas do processo de desenvolvimento, de sua origem ao acompanhamento e avaliação. Tratar das atitudes negativas, com a falta de serviços ou do pronto acesso para eles e outras barreiras prejudiciais sociais, econômicas e culturais beneficiará toda a sociedade. "Neste Dia Internacional dos Deficientes, eu peço aos governos, à sociedade civil e à comunidade global que trabalhem para e junto às pessoas com deficiência para alcançar um desenvolvimento inclusivo, sustentável e igualitário em todo o mundo" (Tradução: Romeu Kazumi Sassaki) (Ban Ki-moon apud FONSECA, 2012, p. 28-9).

Percebe-se que depois de 7 anos do pronunciamento do então Secretário Geral da ONU, apesar dos avanços na conscientização sobre os direitos das pessoas com deficiência em vários países, ainda persistem grandes desafios a serem superados como: a pobreza e a privação de tratamentos de saúde, altas taxas de desemprego de deficientes e ausência de crianças deficientes nas escolas. Estes dados constituem um atraso e confirma a inaplicabilidade dos direitos da pessoa com deficiência. Nas palavras de Ban Ki-moon "(...) o desenvolvimento só pode ser sustentável quando é igualitário, inclusivo e acessível a todos. Pessoas com deficiências precisam, portanto, ser incluídas em todas as etapas do processo de desenvolvimento, de sua origem ao acompanhamento e avaliação" (BAN KI-MOON, apud., FONSECA, 2012, p. 28).

Por essa razão, é imprescindível garantir uma inclusão efetiva da pessoa com deficiência. Para tanto, é necessário a participação do Estado, da família e da sociedade civil para que se possa promover efetivamente o ingresso do deficiente na sociedade, conforme consta na Constituição Federal do Brasil, de 1988.

Costa e Fuzzeto corroboram com a assertiva sobre a fala de efetividade dos ditames legai, ao afirmarem que:

[...] embora não esteja em forma plena, a inclusão social brasileira está em desenvolvimento. É inegável que o papel do Estado seja importante na busca da integração social. Ao aceitar a empreita, a ideia de que a pessoa com deficiência seria subumana foi sendo extirpada com o transcorrer histórico. Todavia, nota-se que o preconceito está entranhado na base da sociedade e, mesmo após séculos de progresso, ainda assombra grupos minoritários (COSTA; FUZZETO, 2017, p. 410).

Diante disso, não se pode olvidar que o Estado, embora tenha declarado tais direitos e garantias em diversos instrumentos normativos, é ineficiente em relação ao fiel cumprimento desses dispositivos e, também a sociedade civil mantem este comportamento desprezível. A inclusão é um direito/dever de todos e não basta a simples corporificação no ordenamento jurídico. É necessário ir além, com ações que a efetivem, ao contrário não passará de uma utopia.

Os estudos constatam que se pode sintetizar o processo histórico da pessoa com deficiência em quatro fases: a primeira traduz-se nas práticas de extermínio e abandono dos deficientes, com a justificativa de que estes eram frutos do pecado e do castigo divino; a segunda fase concerne a invisibilidade da pessoa com deficiência, exclusão caritativa e cultural; a terceira fase coloca a deficiência como uma doença a ser tratada, seguiu o modelo médico, e por conseguinte foi marcada pelo assistencialismo; por fim a quarta, orientada pelos direitos humanos, voltada para a inclusão social e a necessidade de se eliminar os obstáculos que impedem a integração do deficiente na comunidade (PIOVESAN, 2012, p. 46).

Neste sentido, no decorrer da história as pessoas com deficiência foram inferiorizadas pelo fato de serem "diferentes". Estas pessoas foram exterminadas, abandonadas e esquecidas, por não atenderem as exigências sociais de perfeição e, por conseguinte, lhes foram retirados seus direitos fundamentais, sendo tratadas como seres inferiores, descartáveis.

Ao longo da história as graves violações aos direitos humanos tiveram como fundamento a dicotomia do "eu versus o outro", em que a diversidade era captada como elemento para aniquilar direitos. Vale dizer, a diferença era visibilizada para conceber o "outro" como 
um ser menor em dignidade e direitos, ou, em situações limites, um ser esvaziado mesmo de qualquer dignidade, um ser descartável, um ser supérfluo, objeto de compra e venda (como na escravidão) ou de campos de extermínio (como no nazismo) (PIOVESAN, 2012, p. 34).

Assim, percebe-se que as violações dos direitos humanos foram e são pautadas no "eu versus o outro", ou seja, a diferença foi, e é usada como justificativa para cercear direitos e colocar as minorias em situação de inferioridade em relação às demais pessoas, que se entendem "eficientes", nos padrões delineados pela sociedade, de modo geral.

\title{
2 EVOLUÇÃO DOS SIGNIFICADOS E PERCEPÇÃO DE MODELOS DE DEFICIÊNCIAS DECLARADOS
}

Ao longo da história a compreensão da deficiência sofreu diversas modificações. O significado de deficiência foi e é influenciado pelas ideologias de cada época, assim, as expressões adotadas são fundamentadas na espiritualidade e assistencialismo, e, recentemente, com o avanço da ciência e a conscientização sobre a responsabilidade social, tem-se discutido algumas impropriedades sobre diversos termos adotados.

Nesse sentido, compreender a evolução das terminologias determinadas nas normas e orientações sobre os direitos de pessoas com deficiências, em diversas fases históricas é oportuno no presente estudo.

\subsection{Evolução das terminologias adotadas para identificação de pessoas com deficiência}

A Declaração dos direitos das Pessoas Deficientes, aprovada pela Assembleia Geral da ONU, em 09/12/75, apresentou o termo "pessoas deficientes" para se referir a qualquer pessoa incapaz de assegurar por si mesma, total ou parcialmente, as necessidades de uma vida individual ou social normal, em razão de uma deficiência, congênita ou não, em suas capacidades físicas ou mentais.

O Programa de Ação Mundial para as Pessoas Deficientes Documento das Nações Unidas, pela Resolução 37/52, de 03 de dezembro de 1982, dispõe sobre as definições de deficiência, incapacidade e invalidez, que são adotadas pela OMS, nos seguintes termos:

\begin{abstract}
A Organização Mundial de Saúde (OMS), no contexto da experiência em matéria de saúde, estabelece a seguinte distinção entre deficiência, incapacidade e invalidez. Deficiência: Toda perda ou anomalia de uma estrutura ou função psicológica, fisiológica ou anatômica. Incapacidade: Toda restrição ou ausência (devido a uma deficiência), para realizar uma atividade de forma ou dentro dos parâmetros considerados normais para um ser humano. Invalidez: Uma situação desvantajosa para um determinado indivíduo, em consequência de uma deficiência ou de uma incapacidade que limita ou impede o desempenho de uma função normal no seu caso (levando-se em conta a idade, o sexo e fatores sociais e culturais) (Comissão de Direitos Humanos e Minorias (CDHM).
\end{abstract}

No Brasil o tema foi tratado pela primeira vez, lembra Araújo (2012, p. 52), de forma explícita, na Constituição Federal de 1967, com a Emenda Constitucional nº 12, de 17 de outubro de 1978, com o uso da expressão "deficiente".

A CF/1988 fez uso do termo "pessoa portadora de deficiência", e garantiu os direitos fundados no princípio da igualdade, tanto em seu viés formal como no material, e garantiu: percentual dos cargos e empregos públicos, reservados para pessoa com deficiência, dispõe o artigo 37, inciso VIII; e, além disso, garantia de um salário mínimo de benefício mensal à pessoa portadora de deficiência, como determina o artigo 203, inciso V. 
A respeito das declarações constitucionais Araújo (2012) é contundente ao apontar as seguintes críticas:

Muitos desses dispositivos dependiam de leis, que, por sinal, demoraram quase uma eternidade, revelando o descuido do Poder Público com o tema [...]. Um exemplo é o direito a acessibilidade, que só foi garantido em 2000, com a Lei n. 10.098. Passaram-se, portanto, doze anos até que o Poder Legislativo elaborasse a lei que garantia a acessibilidade. Mesmo assim, os prazos ficaram para o decreto regulamentar, que demorou mais quatro anos para ser feito (ARAÚJO, 2012, p. 53)

Antes da ratificação da Convenção sobre os Direitos das Pessoas com Deficiência e seu Protocolo Facultativo, assinados em Nova York, em 30 de março de 2007, no ordenamento jurídico brasileiro discutia-se sobre a melhor terminologia a ser aplicada: pessoa com deficiência, pessoa portadora de deficiência ou deficiente, pessoa com necessidades especiais ou pessoa portadora de necessidades especiais, excepcionais ou pessoa especial.

Estas diversas expressões adotadas, tanto em leis quanto na informalidade, são criticadas por Fonseca (2012), ao afirmar incisivamente que:

Os eufemismos inicialmente citados, todavia, não são a melhor alternativa, visto que mascaram o assunto e preservam a exclusão de modo quase leviano e evidentemente nebuloso e impreciso. Por exemplo: o que é "pessoa portadora de necessidade especial"? As gestantes, os idosos, os namorados apaixonados, enfim, todos nós temos necessidades especiais em circunstâncias específicas, mas, certamente, nenhum de nós as "porta", uma vez que não são objetos. Trata-se, aqui, de um erro evidente, tanto de definição do conteúdo, quanto de concordância nominal e verbal. Todos nós somos especiais em se considerando o princípio da dignidade humana como nota distintiva de cada indivíduo. "Pretendo, com isso, demonstrar a necessidade de clareza, até porque a capacidade ou incapacidade da pessoa com deficiência nada tem a ver com suas condições pessoais, seus impedimentos físicos, mentais, intelectuais ou sensoriais" (FONSECA, 2012, p. 22).

Na Convenção da ONU, que tratou dos Direitos da Pessoa com Deficiência, adotou-se a expressão "pessoa com deficiência". Fonseca (2012, p. 22), explica que se partia da seguinte máxima: nothing about us without us - Nada Sobre Nós, Sem Nós -, que refletia os anseios dos deficientes em romper com as políticas, tutelar e assistencialista, que impediam a autonomia dos deficientes, colocando-os como coadjuvantes em suas próprias vidas.

Matos e Oliveira (2016), ao analisarem os termos discutidos, e, do mesmo modo a pertinência temporal, as lutas e as questões políticas, argumentam:

Se o discurso posterior à incorporação formal insiste em higienizar o pano de fundo da formulação normativa, certo é que nada se criou por benesse, mas sempre em razão de lutas ininterruptas. A propósito, o conhecido slogan do movimento das pessoas com deficiência, "Nada Sobre Nós, Sem Nós", veiculado desde a década de 80, reforça a trajetória de pressão do grupo para participar ativamente de decisões relativas a políticas públicas que lhes dissessem respeito, após séculos de invisibilidade, de subjugação e de dependência às escolhas alheias (MATOS; OLIVEIRA, 2016, p. 17).

Destarte, trata-se de assunto que transcende a razão, todavia, não se quer aqui colocar tão somente emoção, pois, as circunstâncias requerem atitudes pautadas nas necessidades imprescindíveis, de cada um que experimenta limitação de qualquer natureza, de sua essência, e o uso de expressões é questão para segundo plano.

A definição de deficiência tratada na CF/1988, pautada na validação pelo Brasil, da Convenção da ONU a respeito dos Direitos das pessoas com deficiência, conforme Fonseca (2012, p. 22) ultrapassa o aspecto clínico e assistencialista que pautava a legislação anterior. $\mathrm{O}$ autor ressalta o fator político para se reconhecer a necessidade de superar as barreiras sociais, políticas, tecnológicas e culturais. 
Por ser signatário deste importante acordo, e consequente inclusão desses direitos na CF/1988, e posteriormente, a estruturação do Estatuto da Pessoa com Deficiência, Lei 13.145/ 2015, orienta Araújo (2012, p. 55) que a deficiência passa a ser entendida como parte da pessoa, integrando-se a ela, e não algo que estava perto em virtude de posse ou portabilidade. Assim, a pessoa não carrega uma deficiência; ela é deficiente.

Assim, a legislação brasileira vigente, principalmente o Estatuto da Pessoa com Deficiência, é promulgado com o desígnio norteador ao alcance de proteção, inclusão e garantia dos direitos da pessoa com deficiência, em atenção a estes anseios, que por séculos foram esquecidos, afastados ou impedidos de viverem suas vidas com dignidade e cidadania.

\subsection{Modelo Médico e Modelo Social}

Hodiernamente, têm-se dois modelos extremos que discutem o conceito de deficiência denominado modelo médico e modelo social, todavia, é muito difícil encontrar um conceito apenas médico ou apenas social.

No modelo médico, também denominado de modelo individual ou conceito clínico, orienta Altaman, apud., HOSNI, 2016, p. 40), utiliza-se como alicerce a autoridade científica, que identifica e classifica determinada patologia e confere-lhe um prognóstico padrão.

Este modelo constava na primeira classificação do fenômeno nas Nações Unidas em 1980, seguia-se a classificação de deficiência do International Classification of Impairmentes, Disabilitie and Handcaps (ICIDH) da OMS - Comissão Nacional de Relatório de Atividades. Em linhas gerais, o modelo médico, trata a deficiência como uma patologia, advinda de disfunções ou perdas estruturais do corpo que conduzem a deficiência.

Desse modo, a deficiência é tratada como objeto de intervenção médica, podendo ser curada para que o deficiente possa ser reabilitado para viver em sociedade. Com essa inserção do deficiente na sociedade, o mesmo não seria mais alvo de discriminação e preconceito. Assim, o ambiente nesse modelo é um elemento do qual as pessoas devem se adaptar e não o contrário (SILVERS, apud., HOSNI, 2016, p. 41).

O modelo social foi fundado pela Union of Physically Impaired Against Segregation (UPIAS), proposto na Inglaterra, em 1975. Os debates acerca dos princípios fundamentais da deficiência, argumenta Terzi, apud., Hosni, (2016, p. 42), ocorreram entre a UPIAS e a Disability Alliance foram publicadas em 1976.

Hosni (2016) apresenta e discute uma mudança de paradigmas que transcende o caráter assistencialista do tratamento político-social ideal, argumentando que:

A UPIAS propõe uma virada na luta por políticas sociais. Até então as reivindicações eram de caráter assistencialista, que incluía a solicitação de benefícios governamentais. Em contraste, foi proposta a luta pela real inclusão social do grupo, de modo que possibilitasse aos deficientes a independência para conduzir suas próprias vidas (HOSNI, 2016, p. 42).

Nesta acepção, a deficiência não era compreendida como disfunções ou perdas estruturais, uma vez que estas são variações normais do ser humano. A deficiência seria decorrente das limitações sociais, ou seja, do meio social, que impedem o livre acesso, desenvolvimento e autonomia do deficiente e, então, continua Hosni:

O conceito era assim colocado: deficiência é uma situação, causada por condições sociais, que requer para a sua eliminação (a) que nenhum aspecto como pensões, mobilidade ou instituições, seja tratado de forma isolada, (b) que as pessoas deficientes, com a ajuda das demais pessoas, assumam o controle de suas idas, e (c) que os profissionais e especialistas 
que procuram ajudar se comprometam com a promoção do controle pelas próprias pessoas deficientes (HOSNI, 2016, p. 42-3)

Acreditava-se que em uma sociedade perfeita não existiria deficiência e, logo, não existiria discriminação. Esta teoria é rebatida por autores que entendem que algumas deficiências existiriam, mesmo em uma sociedade perfeita. Diniz, apud., Hosni (2016, p.44), comenta que existem pessoas que jamais poderão ter uma vida autônoma e produtiva.

No mesmo sentido Silvers, apud., Hosni (2016, p.44) explica que ao promover certos padrões de independência na comunidade de deficientes, o modelo social excluiu os que nunca conseguirão alcançar certos padrões. Não se pode esquecer que as mudanças no ambiente social são imprescindíveis, mas existem pessoas que jamais alcançaram uma vida "normal", em pé de igualdade como as demais pessoas. Este é o caso dos deficientes intelectuais ou mentais, explicam Mcmahan, apud, Hosni (2016, p. 45).

O fato de não se poderem ignorar as experiências subjetivas da deficiência também é criticado, pois isto é fundamental para se compreender a este fenômeno e elemento identificador, conforme Silvers, apud., Hosni, (2016, p. 45). "Pode-se perceber como sua abordagem limitada e politicamente enviesada, apesar de muito importante, pode não atender às diversas necessidades daqueles que precisam lidar com o fenômeno" (HOSNI, 2016, p. 46).

As abordagens médica e social devem ser observadas e analisadas, pois são complementares, quer seja no meio acadêmico, quer seja para levantamento de dados e informações. É imprescindível uma classificação detalhada da deficiência, pois, na concepção de Barnes, apud Hosni (2016, p. 41) a partir de interpretações pode-se compreender melhor esse tema tão importante.

As divergências conceituais e suas consequências são tratadas por Di Nubila e Buchalla, evidenciando o grau de complexidade e a necessidade de aprofundamento nesta abordagem. Afirmam as autoras que:

A definição e a mensuração da incapacidade tornaram-se tema de crescente interesse, em especial a partir do momento em que as pessoas começaram a viver mais tempo, quando aumentaram as doenças crônicas e suas consequências. A falta de uma definição clara de "deficiência ou incapacidade" tem sido apresentada como um impedimento para a promoção da saúde de pessoas com deficiência. A vigilância e a intervenção dependeriam da capacidade para identificar as pessoas que deveriam ser incluídas nesta definição (DI NUBILA; BUCHALLA, 2008, p. 325)

Assim, não se pode ignorar um conceito, em detrimento do outro, o contrário, ambos precisa ser analisado conjuntamente, como um todo, pois, com base nestes conceitos que serão desenvolvidos e repensados novos conceitos, mais apropriados. É importante analisar as falhas e equívocos cometidos no passado para que não se repitam no presente e, consequentemente, no futuro, para que haja um tratamento respeitoso e compatível com os direitos declarados no ordenamento vigente, nacionais e internacionais.

\subsection{A influência das classificações internacionais na definição de deficiência}

$\mathrm{Na}$ OMS existem duas classificações que servem de referências para a descrição e classificação do estado de saúde, explicam Di Nubila e Buchalla (2008, p. 324): a Classificação Estatística Internacional de Doenças e Problemas Relacionados à Saúde, que corresponde à décima revisão da Classificação Internacional de Doenças (CID-10) e a Classificação Internacional de Funcionalidade, Incapacidade e Saúde (CIF).

A Classificação Internacional de Doenças (CID) surgiu com o propósito orientar sobre o reconhecimento das causas de mortes. Posteriormente seu uso foi ampliado para codificar situações 
de pacientes hospitalizados. Na sequência passou a ser utilizada nas consultas de ambulatório e atenção primária. A sua Décima Revisão, denominada "Classificação Estatística Internacional de Doenças e Problemas Relacionados à Saúde", ou de forma abreviada "CID-10", é a mais recente, denominada "Classificação de Bertillon” de 1893, orientam DI NUBILA; BUCHALLA (2008, p. 326)

Estas classificações passaram por diversas adaptações na medida em que os usuários foram percebendo que apenas uma classificação de doenças não seria suficiente para abarcar todas as questões relacionadas à saúde. De acordo com essas premissas a CID seria uma forma geral classificatória de informações diagnósticas, e outras classificações seriam usadas conjuntamente, tratando de formas diferentes as informações sobre procedimentos médicos e cirúrgicos e as suas incapacidades, entre outros (DI NUBILA; BUCHALLA, 2008, p.326).

A escassez da Classificação Internacional de Doenças (CID) levou a OMS a criar um modelo próprio de compreensão de deficiência:

A International Classification od Impairments, Disabilities, and Handicap (ICIDH) foi elaborada na década de 70 e lançada em 1980. Nessa classificação, as disfunções e perdas estruturais (impairment), as incapacidades ou deficiências (disabilities) e as desvantagens são tratadas como consequências de doenças ou desordens, estabelecendo-se uma relação causal da doença até a desvantagem social. Assim, é um conceito mais próximo da abordagem médica (HOSNI, 2016, p. 46)

Nota-se que no ICIDH adotou-se o conceito médico ao definir a deficiência como: “qualquer restrição ou ausência (resultante de uma disfunção ou perda estrutural do corpo) de habilidade de efetuar uma atividade de maneira normal - ou dentro de um espectro considerado tal - para o ser humano" (HOSNI, 2016, p. 47). Assim, a deficiência é representada por qualquer espécie de anormalidade em nível individual que impeçam o ser humano a exercer determinadas atividades diárias, que são de fácil execução para as demais pessoas. A deficiência neste conceito é caracterizada pelas disfunções ou perda estrutural do corpo, e, portanto, são individuais.

No que diz respeito a desvantagem, Hosni manifesta explica que:

Uma desvantagem para um indivíduo é uma situação resultante de uma disfunção ou uma deficiência que limita ou impede o desempenho de um papel que é normal (dependendo de idade, sexo, e outros fatores sociais e culturais) para aquele indivíduo (HOSNI, 2016, p. 48).

Desse modo, as desvantagens são as situações que impedem o indivíduo de exercer qualquer tarefa que é normal para outro indivíduo (auto sobrevivência), em razão de alguma disfunção ou uma deficiência. Neste sentindo, pode-se subentender que deficiente é responsável pela sua adaptação social, uma vez que este deve se encaixar nos parâmetros e regras da sociedade (HOSNI, 2016, p. 49). Nesta definição, Hosni argumenta que:

O ICIDH foi alvo de várias críticas, especialmente referente à ausência de visão da sociedade como causa de determinados aspectos da deficiência. O que levou a OMS a repensar seu modelo. Durante as décadas de 1980 e 1990 a OMS começou a dar novo rumo à sua abordagem. Nos anos de 1983 a 1992 foram dedicados ao tema, sendo nomeados de década da Pessoa com Deficiência das Nações Unidas (HOSNI, 2016, p. $50)$.

A partir destas premissas a OMS realizou vários trabalhos, estudos de campo e consulta internacional, que começaram em 1990, e desenvolveu a "International Classification of functioning, disability and Health, que teve sua aprovação para o uso internacional em maio de 2001, traduzida para o português como Classificação Internacional de Funcionalidade, Incapacidade e Saúde CIF” (DI NUBILA; BUCHALLA, 2008, p. 326). 
A CIF é consequência do progresso da ICIDH, e também faz parte da Classificação Internacional de Doenças e Problemas Relacionados a Saúde (CID). A ICIDH e a CIF partiram da necessidade de precisão de inferir sobre as questões não abordadas pela CID.

Por essa razão, a CIF foi intitulada como segunda edição da ICIDH, e reproduziu o conhecimento e o pensamento de uma década diferente. A CIF foi elaborada no decorrer de duas décadas que compõem as mudanças nas concepções no modelo de classificação. Uma participação ativa de organizações como a Rehabilitation International (RI) tiveram atuação importante nas questões conceituais, ao longo das revisões sucessivas da CIDID/ICIDH, até a versão final da CIF. Envolveram, inclusive, 50 países e 1.800 peritos com todos os colaboradores, grupos de trabalho específicos para algumas áreas, instituições e redes internacionais representativas de pessoas com deficiências. Todas as discussões e deliberações foram disponibilizadas, em seis idiomas oficiais, na página de classificação da OMS e publicadas, em língua portuguesa, para todos os países lusófonos em novembro de 2003. Em relação a este avanço Di Nubila e Buchalla (2008, p. 326), explicam que:

A CIF, assim, é uma proposta de integração das abordagens médica e social da deficiência, gerou a ideia de que: [a] funcionalidade e a incapacidade [disability] de uma pessoa são concebidas como uma interação dinâmica entre os estados de saúde (doenças, perturbações, lesões, traumas, etc.) [mpairments] e os factores contextuais. (...) A incapacidade [disability] é caracterizada como o resultado de uma relação complexa entre a condição de saúde do indivíduo e os factores pessoais, com os factores externos que representam as circunstâncias nas quais o indivíduo vive. CIF é meramente descritiva de aspectos que caracterizam a deficiência em si e estabelece uma linha entre quem é deficiente e quem não é (OMS, apud HOSNI, 2016, p. 52, 53 e 55).

Neste sentido, Di Nubila e Buchalla (2008, p. 327), esclarecem que a CIF retrata os aspectos de funcionalidade, incapacidade e saúde das pessoas, possui caráter multidisciplinar, pode ser aplicada em todas as culturas, e traz, pela primeira vez, a incorporação dos aspectos de contexto mais profundo. Por esse motivo esta classificação é mais complexa que a CID, o que faz com que se exija um maior detalhamento desta classificação.

Assim, os países membros da OMS devem adotar a CID-10 para apresentar estatísticas das causas de morte ou das doenças que levam a internações hospitalares ou atendimentos ambulatoriais. Atualmente, explicam Di Nubila e Buchalla (2008, p. 327), consiste na classificação diagnóstica padrão internacional para propósitos epidemiológicos gerais e administrativos da saúde, inclui-se análise de situação geral de saúde de grupos populacionais e o monitoramento da incidência e prevalência de doenças e outros problemas de saúde.

A CIF não aponta quem é 'normal' e quem é 'incapaz'. O uso da CIF permite que uma pessoa ou um grupo possa ser identificado como tendo 'incapacidade' em cada contexto ou uso, conforme apresentado pela OMS em 2013. A CIF não classifica as pessoas, e sim as funcionalidades ou incapacidades experimentadas.

Conforme orientações de Di Nubila e Buchalla:

$\mathrm{O}$ desenvolvimento de uma terminologia formal relacionada à funcionalidade e a incapacidade constitui um desafio, especialmente devido à ambiguidade conceitual dentro deste campo. A CIF é uma grande fonte de termos relevantes, conceitos e relações necessárias para o desenvolvimento de terminologias formais, e assim oferece um importante ponto de partida neste desafio (DI NUBILA; BUCHALLA, 2008, p. 329).

Desse modo, a CIF organiza as suas informações em duas partes. A OMS orienta que a parte um envolve a funcionalidade e a incapacidade, e, a parte dois, trata de fatores contextuais. A primeira parte compreende as Funções Corporais, que são as funções fisiológicas ou psicológicas dos sistemas do corpo; Estruturas Corporais, consistentes nas partes anatômicas do corpo, tais como órgãos, membros e outros componentes; Deficiências, correspondendo aos problemas nas disfunções ou perdas da estrutura do corpo ou desvio considerável; Funcionalidade, que trata dos 
aspectos de interação do indivíduo com alguma condição de saúde, entre os fatores contextuais do mesmo (fatores ambientais e pessoais); Incapacidade, configurado pelo inverso a funcionalidade, denota os aspectos negativos da interação do indivíduo com o seu meio, envolve a não funcionalidade em um ou mais dos mesmos níveis: deficiências, limitações de atividade e restrições à participação.

Nesse diapasão, a CIF traz informações de forma sistemática, que servem como padrão e possibilitam a classificação da deficiência, sem que acarrete discriminações. Existe uma relação dinâmica entre a funcionalidade e a incapacidade, a primeira, como vista neste estudo, consiste na interação do indivíduo, juntamente com os fatores ambientais (externos) e pessoais (internos), e, a funcionalidade corresponde aos aspectos negativos destas interações traduzidas nas limitações de atividades e restrições à participação do indivíduo com o seu meio. Di Nubila e Buchalla (2008, p. 330) esclarecem que:

Um indivíduo pode apresentar uma deficiência (no nível do corpo) e não necessariamente viver qualquer tipo de incapacidade. De modo oposto, uma pessoa pode viver a incapacidade sem ter nenhuma deficiência, apenas em razão de estigma ou preconceito (barreira de atitude).

A segunda parte, descritos pela OMS, 2013, diz respeito aos fatores ambientais e pessoais. Aqueles são fatores externos ao indivíduo, como: atitudes sociais, características arquitetônicas, estruturas legais e sociais, bem como clima e terreno; e estes, são fatores internos, que incluem gênero, idade, estilo de vida, condição social, educação, profissão, experiências passadas e presentes, padrão de comportamento geral, caráter e outros fatores que influenciam a maneira como a incapacidade é sentida pelo indivíduo.

Di Nubila e Buchalla (2008, p. 331) explicam que ambas, CID-10 e CIF, são amplas e podem descrever qualquer estado de saúde ou de funcionalidade, sem definir limites. A CID-10 faz parte do modelo da CIF, colocada no lugar reservado às condições ou estados de saúde, aliado aos distúrbios ou doenças. Este modelo se mostra como o mais próximo da descrição da experiência de incapacidade vivida pelos indivíduos em qualquer condição de saúde, e, portanto, auxilia na compreensão da situação dinâmica de interação do indivíduo em um determinado contexto.

Assim sendo, é imprescindível a participação do poder público e dos formuladores de políticas nas discussões de definições e avaliações, que na compreensão de Di Nubila e Buchalla (2008, p. 333), devem ser mais claras e justas, no que diz respeito à deficiência ou incapacidade, e, então, a CIF é aplicável a todas as pessoas, independentemente de suas condições de saúde.

As autoras Di Nubila e Buchalla (2008, p. 331) evidenciam a extensão da CIF e demostram sua importância, uma vez que podem ser utilizadas em vários setores, como saúde, previdência social, do emprego, da educação e transportes, entre outros, para avaliar o estado funcional das pessoas. Apontam que a CIF foi usada como padrão para caracterização da deficiência na proposta do Estatuto da Pessoa com Deficiência, apresentada em consulta pública ao Senado Federal, mesmo antes de sua edição, embora esta menção tenha desaparecido e reaparecido em minutas subsequentes (p.333).

Desse modo, a CIF é uma classificação humanitária das funcionalidades e incapacidades, pois não rotula a pessoa ou a discrimina, e tem como objetivo descrever apenas os contextos que causam a deficiência. Orienta que a deficiência é fruto do meio ambiente, mas também reconhece os fatores pessoais. Esta classificação é a combinação dinâmica entre o modelo médico e o modelo social, haja vista que não se nega que a deficiência é uma patologia, mas admite depender dos fatores ambientais, ou seja, do meio social do indivíduo. 


\section{CONCLUSÃO}

O estudo evidenciou que as pessoas com deficiência foram alvo de diversos abusos no decorrer da história mundial, justificados, ora pelo poder a divindade, ora pelo simples fato de ser "diferente". Estas pessoas foram excluídas ou exterminadas durante milênios e tais atitudes eram tidas como normais.

A deficiência foi vista, em determinados momentos da história, como uma doença e, portanto, passível de cura, de acordo com o conceito médico. Posteriormente, foi observada como consequência das barreiras sociais e, nesta perspectiva, a deficiência seria um fenômeno social, fruto da discriminação e do preconceito conforme o modelo social.

Surgiram, então, classificações de doenças e limitações quanto a adoção dos indicadores, com o intuito de categorizar a deficiência. No primeiro momento utilizou-se o modelo médico, nesta percepção o deficiente deveria adaptar-se à sociedade e não o contrário, como demostrado no ICIDH. Com a CIF, a deficiência passou a ser analisada como disfunções e incapacidades, relacionadas aos fatores pessoais e ambientais, com o fim de descrever os contextos que levam a deficiência, de qualquer natureza.

Desse modo, com o passar dos anos e em virtude das intensas lutas pelo reconhecimento dos direitos dos deficientes, as lutas de séculos pela inclusão social e a cidadania se intensificaram, a sociedade começou a compreender que a deficiência é algo inerente ao ser humano. Percebeu-se que a deficiência não é algo que se porta, carrega, pois não consiste em uma escolha. $\mathrm{O}$ deficiente não escolhe ser deficiente ele o é, e, qualquer pessoa pode tornar-se deficiente.

Assim sendo, percebe-se que a significação da deficiência sofreu transformações no decorrer da história, de um modo geral. Evidencia-se, de igual modo, a influência das definições e classificações internacionais de deficiência, bem como da influência da Convenção dos Direitos das Pessoas com Deficiência, na qual o Brasil é signatário, e os seus reflexos na legislação pátria, que conduziu a promulgação do Estatuto da Pessoa com Deficiência, que por sua vez introduziu algumas alterações na legislação civil brasileira, todavia, muito há o que se verificar, para que não se cometa injustiças quanto a esta categoria, que por muito tempo esteve submetida ao esquecimento e maus tratos, e ainda isto ocorre. Também, discutir sobre o tema é fundamental para que as impropriedades, quanto à definição, classificação e mensuração das limitações, não sejam aleatórias e destoantes da realidade nacional e internacional.

Finalmente, é inconteste que o Estado e a família atuem ativamente, em conjunto com a sociedade civil, para que sejam realizadas ações acertadas que permita a inclusão da pessoa com deficiência. Acredita-se que aqueles qualificados como "eficientes" possam compreender que, a pessoa com deficiência deve ser vista como integrante da sociedade, ou seja, como um cidadão, e, assim como as demais, merece o reconhecimento de seus direitos, e isto somente poderá ser conquistado com a inclusão social e a materialização da verdadeira cidadania, declarada na Constituição Federal, determinada no Estatuto da Pessoa com Deficiência, que permite sentimento de pertencimento de um indivíduo, ou de um grupo de pessoas, a uma determinada comunidade, e, por sua vez, lhes permitam direitos e obrigações, para que possa viver em harmonia em ambientes diversos, enfim, viver a vida, em sua plenitude.

\section{REFERÊNCIAS}

ANO INTERNACIONAL DAS PESSOAS DEFICIENTES. Comissão Nacional de Relatório de Atividades Brasil, 1981. PDF.

ARAÚJO, A Convenção sobre os direitos das pessoas com deficiência e seus reflexos na ordem jurídica interna no Brasil. Manual dos direitos da pessoa com deficiência. Coords. FERRAZ, 
Carolina Valença; LEITE, George Salomão; LEITE, Glauber Salomão; LEITE, Glauco Salomão. São Paulo: Saraiva, 2012.

BRASIL, Lei 7.853 de 24 de outubro de 1989. Institui a tutela jurisdicional de interesses coletivos ou difusos dessas pessoas, disciplina a atuação do Ministério Público, define crimes, e dá outras providências. - Corde, D.O.U. 24 de out. de 1989. Brasília, DF: Casa Civil, Subchefia para Assuntos Jurídicos, 1989. Disponível em: < http://www.planalto.gov.br/ccivil_03/Leis/L7853.htm>. Acesso em: 02 de jun. 2018.

BRASIL. Constituição Da República Federativa Do Brasil De 05 de outubro de 1988. D.O.U. 05 de out. de 1988. Brasília, DF: Casa Civil, Subchefia para Assuntos Jurídicos, 1988. Disponível em: 〈http://www.planalto.gov.br/ccivil_03/constituicao/constituicaocompilado.htm>. Acesso em: 31 mai. 2018.

BRASIL. Lei no 13.146, de 6 de julho de 2015. Institui a Lei Brasileira de Inclusão da Pessoa com Deficiência (Estatuto da Pessoa com Deficiência). D.O.U. 06 de julho de 2015. Brasília, DF: Casa Civil, Subchefia para Assuntos Jurídicos, 2015. Disponível em: < http://www.planalto.gov.br/ccivil_03/_ato2015-2018/2015/lei/113146.htm>. Acesso em: 31 mai. 2018.

CAIADO, Kátia Regina Moreno. Convenção Internacional sobre os direitos das pessoas com deficiências: destaques para o debate sobre a educação. Revista Educação Especial, v. 22, n. 35, p. 329-338, set./dez. 2009, Santa Maria. Disponível em:

<http://www.ufsm.br/revistaeducacaoespecial>.

ONU, Comissão de Direitos Humanos e Minorias - CDHM. Programa de Ação Mundial para as Pessoas Deficientes. Doc. das Nações Unidas. Resolução 37/52, de 3.12.1982. (Disponível em: http://www2.camara.leg.br/atividade-legislativa/comissoes/comissoes-permanentes/cdhm/comitebrasileiro-de-direitos-humanos-e-politica-externa/ProgAcMundPessDef.html. Acesso em: 02 de jun. 2018).

COSTA, Francisco Lozzi Da; FUZETTO, Murilo Muniz. As pessoas com deficiência e a inclusão social: evolução histórica e ações afirmativas. CAMPELLO, Livia Gaigher Bosio; LANNES, Yuri Nathan da Costa. - (Coord.) Anais do V Congresso Nacional da FEPODI. (org.). Florianópolis: FEPODI, 2017.

ONU, DECLARAÇÃO DOS DIREITOS DAS PESSOAS DEFICIENTES. Resolução aprovada pela Assembleia Geral da Organização das Nações Unidas em 09/12/75. PDF.

DI NUBILA, Heloisa Brunow Ventura; BUCHALLA, Cassia Maria. O papel das Classificações da OMS - CID e CIF nas definições de deficiência e incapacidade. Rev Bras Epidemiol, vol.11, n.2, ISSN 1980-5497. p.324-335, 2008. Disponível em: <http://dx.doi.org/10.1590/S1415790X2008000200014>. Acesso em: 31 mar. 2018.

FONSECA, Ricardo Tadeu Marques. O novo conceito constitucional de pessoa com deficiência: um ato de coragem. Manual dos direitos da pessoa com deficiência. Coords. FERRAZ, Carolina Valença; LEITE, George Salomão; LEITE, Glauber Salomão; LEITE, Glauco Salomão. São Paulo: Saraiva, 2012. 
HOSNI, Davi S.S. O conceito de deficiência e sua assimilação legal. Teoria das incapacidades e o Estatuto da pessoa com Deficiência, Orgs. PEREIRA, Fábio Queiroz; MORAIS, Luísa Cristina de Carvalho; LARA, Mariana Alves. Belo Horizonte: Editora D’ Palácio, 2016.

MARCONI, Marina de Andrade; LAKATOS, Eva Maria. Fundamentos e metodologia científica. 7 ed. São Paulo: Atlas, 2010.

MATOS, Ana Carla Harmatiuk; OLIVEIRA, Lígia Ziggiotti de. Além da convenção de Nova York: além do estatuto da pessoa com deficiência. Reflexões a partir de uma compreensão crítica dos direitos humanos. Revista de Derechos Humanos y Estudios Sociales, n. 15 p. 15-32, jan.jul. 2016.

OMS, Organização Mundial da Saúde. Como usar a CIF: Um manual prático para o uso da Classificação Internacional de Funcionalidade, Incapacidade e Saúde (CIF). Versão preliminar para discussão. Outubro de 2013. Genebra: OMS.

PIOVESAN, Flávia. Convenção da ONU sobre os direitos das pessoas com deficiência: inações, alcance e impacto. Manual dos direitos da pessoa com deficiência. Coords. FERRAZ, Carolina Valença; LEITE, George Salomão; LEITE, Glauber Salomão; LEITE, Glauco Salomão. São Paulo: Saraiva, 2012. 